\title{
Interface for Intelligence Computing Design and Option of Technical Systems
}

\author{
Javanshir Mammadov, Tarana Tagiyeva, Akhmedova Sveta, Aliyeva Arzu \\ Department of "Information Technology and Programming" of Sumgait State University, Sumqayit, Azerbaijan \\ Email: cavan62@mail.ru
}

Received 14 September 2015; accepted 21 November 2015; published 24 November 2015

Copyright (C) 2015 by authors and Scientific Research Publishing Inc.

This work is licensed under the Creative Commons Attribution International License (CC BY). http://creativecommons.org/licenses/by/4.0/

CC) (i) Open Access

\begin{abstract}
As a result of analysis of the existent methods and tools of computer aided design of the technical systems of many industrial areas, the primary purpose of the article that consists in the decision of different project problems within the framework of one programmatic system with the use of comfortable programmatic interface is certain. Architecture of the program interface for computer designing and option of technical systems of different industrial areas on the basis of stage-bystage automated designing principles with using programmatic and informative supports is worked out. In the article, the problem of computer designing, searching and option of elements of manipulator for flexible manufacture module is considered. As a method of logical simulation of the problem, production model of designing procedures of the program interface and intelligence option of a manipulator, its technical parameters are developed. On the basis of algorithmic scheme of searching, the option of a manipulator from data base is worked out.
\end{abstract}

\section{Keywords}

Computer-Aided Design, Design Stages, Production Model, Programmatic Interface

\section{Introduction}

As known many technical objects (TO) (types of TO are showed in poster) are designed by means of standard stages (requirement specification, technical suggestion, draft design and detail design) with using CAD systems [1] [2]. Architecture of program interface is worked out in corresponding to the designing stages by the system's menus and special systems. Analysis worked out separate tool of the programmatic, informative and mathematical providing for the automated planning on the stages of planning that provided application and realization of technical, programmatic, informative, mathematical etc. A tool in the different areas of industry showed that they properly did not provide universality and complex planning of the difficult technical systems [3] [4]. 
In this connection, decision of problem on development of the intelligence programmatic system of computeraided design, providing complex approach of realization of the automated procedures and operations on the basic stages of planning from the scientific point of view is an actual and priority problem and direction.

Being base on principles of universality, openness and planning flexibility, as a primary purpose of project is offered software for a complex computer-aided design, where up basis the structure of the stages of planning of the technical systems, programmatic procedures and executive directives, and also interface, takes with the programmatic modules of the database management system, by CAD of circulation of documents, processing of documents, subsystem of computer experiments, system of automation of mathematical calculations and in-plant, global computer system, computer graphics and multimedia.

\section{Solution of the Problem}

The primary purpose of the project is development of the single intellectually-operating system of designer for complex computer-aided of technical objects of the different setting design. Scheme of interface of the intellectually-operating system of designer (IOSD) of the complex designing is offered with the following blocks of menu:

1) Designing stages;

2) Project programs;

3) Programmatic-operating functions.

Work of IOSD is based on stage-by-stage approach since the entry of basic data and application of planning object domain to creation of detail design. IOSD allows controlling the universal programmatic interface on the basis of intellectually-operating functions of complex computer-aided of the technical systems of the different setting design.

In a depended on analyze of progressive status of CAD the following research problems have to solve:

1) Development of the common scheme of computing design with program interface;

2) Development of first panel of "Designing stages" with its menus and program operations;

3) Development of second panel of "Project programs" with its menus and program objects;

4) Development of third panel of "Programmatic-operating functions" with its menus and service operations;

5) Providing cooperation of the system with program functions of a corporate network;

6) Program control of design information of the IOSD on the level of technical provide.

The programmatic package of interface for a complex computer-aided of technical objects design is developed on the base of instrumental programmable environment of Delphi; procedures of logical search and choice of information on the stage of technical suggestion developed on the base of intellectual programmable environment of Prolog and database management systems, control system of base of the designed data; procedures of engineering design will be realized on the basis of the prepared designer and technological programmatic tool of AutoCAD [5].

The basic idea of project consists in the decision of different project tasks within the framework of one programmatic system with the use of comfortable programmatic interface.

\subsection{Architecture of Programmatic Interface for Computer Designing Procedures}

As it is generally known, great number of technical objects of planning, for development of that required application CAD on the stages of planning exist. In accordance with the stages of planning, the commands of system menu and types of the special programmatic systems are developed the architecture of programmatic interface with the automated procedures on design stages (Figure 1).

On the first stage project procedure of requirement specification will be realized where a standard template is filled depending on an application of technical object domain. The entered data are saved to the database of user-designer. For example, on the special system window design object area, a type of design element, characteristics of the design element and other parameters are chosen. After inputting all design data they are saved in the system base [6].

On the second stage project procedure of technical suggestion will be realized, where the problems of local (in the database of user-designer) and global search decide.

At a global search of the automated choosing a few variants of the projects (in accordance with data of requirement specification) comes true, their animation and video presentation. The final choice of the best variant 


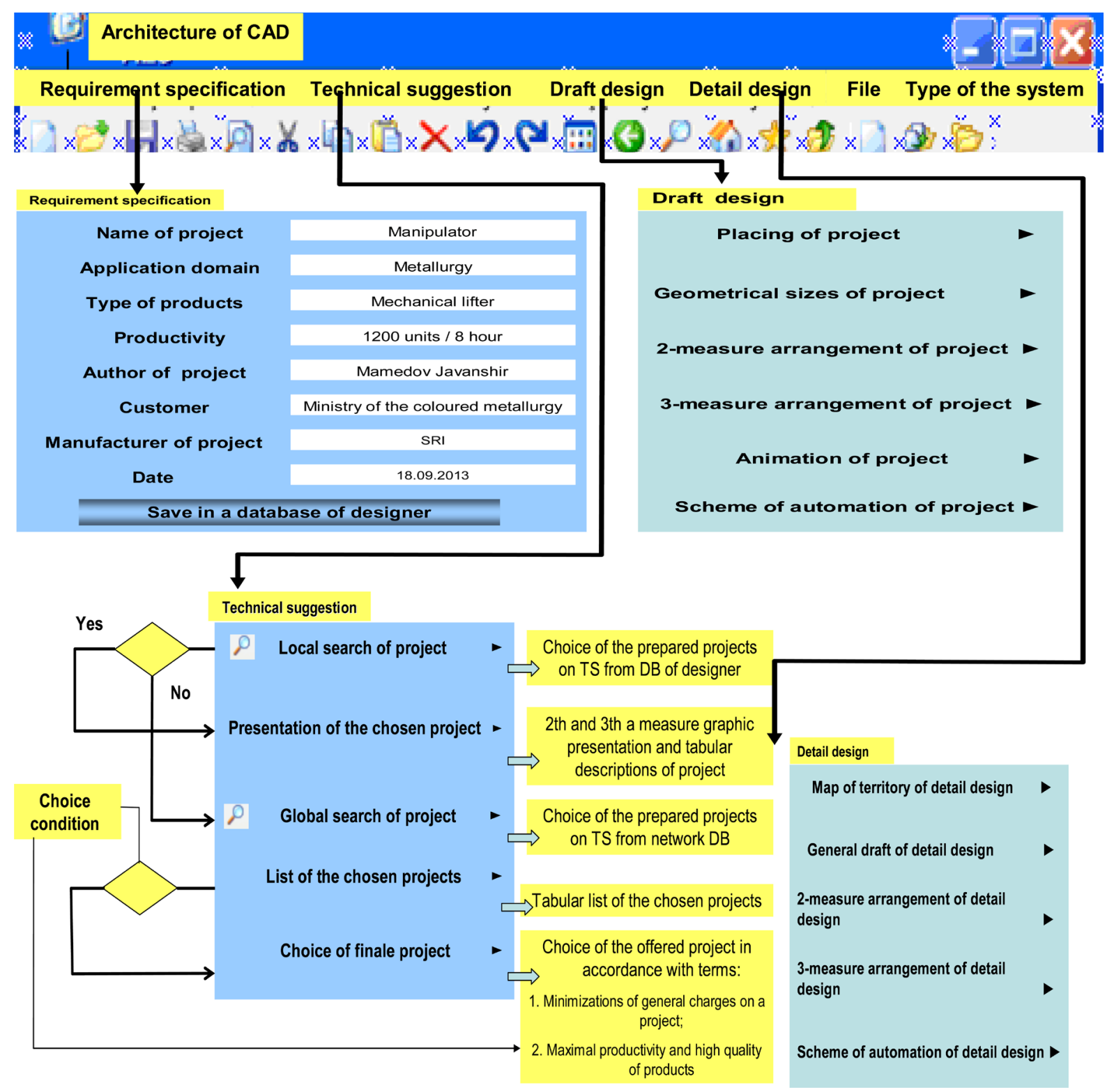

Figure 1. The architecture of programmatic interface with the programmatic procedures on design stages.

comes true in accordance with terms: applications of innovative technologies; to the high yield; producing quality of products; providing reliable automation of planning object; to minimization of material charges and other.

On the third stage procedure of the preliminary planning technical object will be realized. The basic project operations are drafts in two and three projections and 2 and 3-measure images (axonometric presentation of draft) and registration of these (specification and angular stamp of draft) these drafts, animation presentation, and also scheme of automation of planning object [7].

On the fourth stage of the working planning through a menu of final technical documentations get out accordingly for unsealing [8]. On the basis of documentations of detail design of technical objects are practically developed in accordance with productive terms of the design object.

\subsection{Production Procedures of Program Interface of Designing}

For simulation of all functions of the intelligence program interface designing procedures by means of production algorithm is needed to create. Every subsystem and block of architecture of program interface of computing 
design of manipulator of the flexible manufacture module (as shown in requirement specification) will designate as subsystems: Pos—a subsystem of the programmatic-operating system providing functioning of open complex subsystem of computing design of manipulator; $P i$-a subsystem of interface including set of menu for activation of commands, corresponding to the blocks of subsystem of computing design of manipulator and auxiliary subsystems providing flexibility on the whole; Pap_i (where $i=\overline{1,5}$ ) —a subsystem of computing design of manipulator; (Pap_1—a block of computing design of composes structure of manipulator; Pap_2—a block of standard active elements of manipulator; Pap_3-a block of computing design of automation scheme of manipulator; Pap_4-a block of computing design of technical control and diagnostic system of manipulator; Pap_5—a block of computing design of non standard elements of manipulator); Psp_i (where $i=\overline{1,3}$ )—a subsystem of special packets of the applied software and programming-language systems $\left(P_{s p_{1} 1}\right.$-a block of constructor packets on the base of T-FLEX CAD; $P_{s p_{2} 2}$-a block of packets of the applied software for creation of data base and control system of data base; $P_{s p_{-} 3}{ }^{-}$a block of the mathematical packets of the applied software on the base of MathCAD; $P_{s p_{-} 4}$-a block of the applied software on the base of Delphi; $P_{s p_{-} 5}$-a block of the intelligence software on the base of PROLOG;); $P_{b d z} i$ (where $i=\overline{1,4}$ ) - a subsystem of data base and knowledge ( $P_{b d z \_1}$-a block of data base; $P_{b d z \_}-$a block of knowledge base); $P_{a r m_{-} i}$-(where $i=\overline{1,4}$ ) -a subsystem of algorithmically calculation and simulation $\left(P_{\text {arm_ } 1}\right.$-a block of algorithmically calculation; $P_{\text {arm__ }}$-a block of simulation); $P_{p v}$-a subsystem of searching and option; $P_{q s}$-a subsystem of global computer network; $P_{t o}$-a subsystem of technical support with periphery units of design document printing and connection with Internet.

The program operations of interface of computing design of manipulator and its option works are executed as follows:

1) After plugging $\left(t_{1}\right)$ of the operating system $P_{\text {os }}$ in the subsystem of hardware of Pto, through a main menu shell program of the same name of the complex subsystem is opened;

2) Designer using the subsystem of interface of $P i$, which works after including $\left(t_{2}^{1}\right)$, opens the library of subsystem of computer design of $P_{a p_{i} i}$ with the before worked out prepared composes structures, scheme of automation of every manipulator on the whole, and also data base of these standard active elements of $P_{a p_{-} 2}$ and if necessary edits this file and saves the edited information in computer memory.

3) By means of command $\left(t_{2}^{2}\right)$ a designer creates files with new developments of layout chart corresponding to the scheme of automation in the subsystem of computer design of composes structure of $P_{a p_{-} 1}$ and scheme of automation of $P_{a p \_3}$ and technical control and diagnostically of manipulator design in the subsystem of computer design of the technical checking and diagnostically of $P_{a p_{4}}$, kinematics scheme and construction draft of gripper devices, special manipulators in the subsystem of computer design of non-standard active elements of manipulator $P_{a p \_}$.

On the $3^{\text {rd }}$ stage in the process of new file, subsystem of $P_{a p_{-} 1}$ creation, $P_{a p_{-} 2}, P_{a p_{-} 3}, P_{a p_{-} 4}, P_{a p_{-} 5}$ co-operate with the subsystem of the special application packages and programmatic-language system $P_{s p_{-} 1}, P_{s p_{-} 2}$. Thus subsystems of $P_{a p_{-} 1}, P_{a p_{-} 3}, P_{a p_{-} 4}, P_{a p_{-} 5}$ co-operate also with the subsystem of algorithmic calculations and design of $P_{a r}$, $P_{a m}$. For this purpose in a control of open complex subsystem of computing designing of manipulator panel commands get $\left(t_{2}^{3}\right)$ out for drawing of composes scheme or calculation of parameters of non-standard elements and design of scheme of automation of manipulator.

4) On this stage for the wearing-out $\left(t_{3}\right)$ of subsystem of search and choice of $P_{p v}$ of composes structures, active elements the commands of subsystem of database of $P_{b d z \_}$and knowledge of $P_{b d z \_}$get out on the basis of terms-queries. At the choice of database the software environment of the system Microsoft Access is opened and a query is set for a search and choice of the prepared types of active elements with their specifications. At the choice of files of base of knowledge the intellectual programmatic system PROLOG (subsystem of $P_{s p \_5}$ ) is opened where a query is set for a search and choice of elements of control system, worked out non-standard active elements, composes structures and scheme of automation of manipulator on the basis of algorithms of calculation. In case of search of the prepared composes structures of manipulator with standard elements the command of the network including ( $P_{q s}$-subsystem of global computer network) gets out from menu of search. Thus choosing the certificate menu $\left(t_{4}\right)$ of subsystem of global computer network of $P_{q s}$ it is possible to get additional information about open system of the computer designing of manipulator.

\subsection{Procedures of Option of Manipulator on a Stage of the Technical Suggestion of the Program Interface of Designing}

Option of the necessary manipulator project from data base $\left(D B_{i}\right)$ of the designers within the framework of local 
workstation is worked out. A query for option of a project includes the variants of basic data of the requirement specification, which were before saved in $D B_{1}$. In accordance with the expressions from the basic data and technical parameters of a manipulator for more exact option, the following function is given: $f_{1}, f_{2}, \cdots, f_{n}$ are constituents of the function: force of clamping of manipulator $F$, its geometrical sizes.

Taking into account the values of mass of the manipulated object of $m_{i j}$ and predominance of mass of the manipulator of $m_{g i j}$ from $m_{i j}$ (coefficients taking into account mass of gripper of $c_{g}$ and taking into account the type of drive of manipulator $\left(M_{i}\right)$ of $c_{d}$ ) by means of the following terms, the manipulator gets out with the required carrying capacity $\left(C_{i}\right)$ :

$$
\text { If }\left(\left[m_{i 1}\right] \Rightarrow M_{i} \cup\left(C_{i}=m_{i 1} c_{g} c_{d}\right)\right)
$$

(where $m_{i 1} \rightarrow c_{g}=1.4 \wedge c_{d}=1.1$ for hydraulic motor),

Then (on the basis of characteristic parameters from a database, the search of the required type of $M_{i}$ is realized).

Thus, the following condition of limitation is taken into account:

$$
C_{i} \leq C_{\max },
$$

where $C_{\max }$-maximal value of carrying capacity of $M_{i}$, that gets out from a database. Accordingly depending on their carrying capacity, type and construction parameters of $M_{i}$ is got out. Maximal tension in the cross runner of the manipulated object allows to choose a drive for manipulator.

Setting the following condition

$$
\text { If }\left(\sigma_{m o} \leq[s]_{u}\right) \text {, }
$$

Then (from the database of the standard drives of gripper of $M_{i}$, the most nearby value of forces of clamp of the manipulated object is got out $\left(F=\sigma_{m o} S\right), S$-area, which exposed to the clamp $\left.\left(\mathrm{mm}^{2}\right)\right) \&\left(\left(F-F_{s t}\right) \rightarrow \min\right.$, where $F_{c m}$-standard value of clamping $M_{i}$ ).

Summarizing the conclusions of stage-by-stage realization of architecture of interface of the computer designing of manipulator and its option it should be noted that taking into account the basic requirements to creation of instrument of the computer design of manipulator, subsystems provide universality, adaptively and flexibility of the system at development of manipulator of different areas of metallurgical industry.

The subsystems of the algorithmic, mathematical providing, expert and information retrieval operations used as autonomous blocks provide authenticity, fast-acting and reliability of executable project operations and procedures.

As be obvious from a Figure 1 in a control of computer-aided design panel for creation of new project, opening of existent projects, organization of work with the subsystems of architecture of instrument of the computer designing of manipulator is used procedures of programmatic block "File".

\section{Conclusions}

The basic results of the article are the following:

1) The worked out architecture of computer design and option of technical systems works by principle of the stage-by-stage designing on the basis of the programmatic interface. It provides the complex decision of planning design operations, since the entry of basic data and application of planning object domain to creation of detail design [9] [10].

2) It was given the logical procedures of production model for designing and option of manipulator which provided operative and flexible designing and searching-option operations on the level of one universal program interface.

3) The programmatic interface has practical application during a computer-aided and option of the technical systems for the different setting design.

The proffered intellectually-operating system of designer will allow in future:

1) To decide the problem of complex computer-aided design and option, since the entry of basic data and application of planning object domain to creation of detail design;

2) To manage effectively the universal programmatic interface on the basis of intellectually-operating functions of complex computer-aided of the technical systems of the different setting design;

3) From the presence of great number of logical queries for a search, choice and planning, to promote the lev- 
el of intellectuality of this system;

4) To adapt quickly with procedures of the project programs and the operation system;

5) To use the date system in the mode of on-line dialogue with designers for acquisition necessary project information.

\section{References}

[1] Bozdoc, M. (2003) The History of CAD.

[2] Cunvu Li Basis CAD of CAD/CAM/CAE. “Peter”, Moscow—Sankt Peterburg, 2004, 560 p.

[3] Voronenco, V.P. (2001) Designing of the Manufacture Systems Is in an Engineer: Studies. Manual. Tiraspol: Rio Psu, $349 \mathrm{p}$.

[4] Chelishev B.E. (2004) Computer-Aided of Design of Technology in Machine-Building. Electronic Magazine "Science and Education”. Engineering Education of Association of Technical Universities. AL No. FC 77.

[5] Polovincin, A.I. and Bobkov, N.K. (2004) Bush of G.Y. Automation of the Searching Constructing (Artificial Intelligence Is in the Machine Constructing). Electronic Journal of "Science and Education". Engineering Formation of Association of Technical Universities. AL No. FC 77.

[6] Aliyev, R.A., Mammadov, J.F. and Akhmadov, M.A. (2005) Development of Tool of the Automated Planning of Control System of FMS.-M.: Mechatronic, Automation, Management, No. 9, 27-35.

[7] Mammadov J.F. (2002) Problems and Stages of Development of the Automated Choice and Planning of the Flexible Manufacture Systems. The Redaction of Technical Literature "House of Baku University" of Baku, 175 p.

[8] Mamedov, J.F. and Huseynov, A.H. (2011) Algorithmic and Programmatic Providing of the Automated Layout of the Flexible Productive System. In: Design Information Technologies in Planning and Production, Scientific and Technical Magazine, Moscow, No. 1, 49-52.

[9] Mamedov J.F. (2013) Development of Structure of Interface of Complex Automated Planning of the Technical Systems Software. Moscow. Announcer of Computer and Informative Technologies, No. 5, 18-21.

[10] Golovanov, N. (2014) Geometric Modeling: The Mathematics of Shapes. Create Space Independent Publishing Platform. 